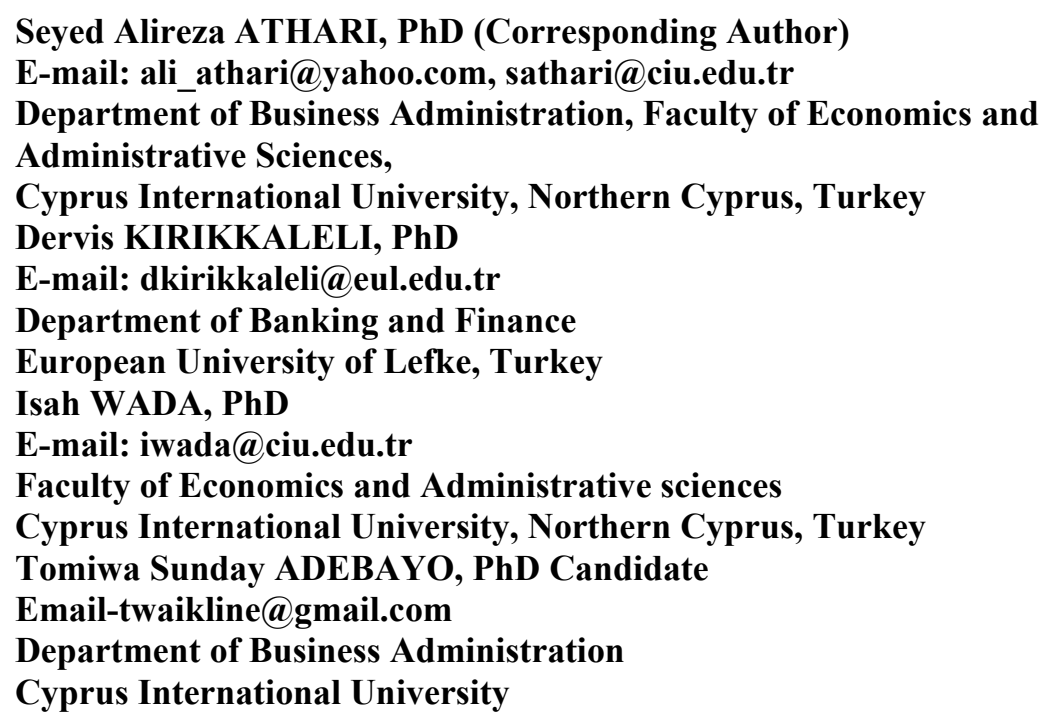

\title{
EXAMINING THE SECTORAL CREDIT-GROWTH NEXUS IN AUSTRALIA: A TIME AND FREQUENCY DYNAMIC ANALYSIS
}

Abstract. This study examines the sectoral credit-economic growth causal nexus in Australia using a wavelet coherence test between 1994Q4 and 2018Q4. For achieving this aim, the main sectors of agriculture, manufacture, and service are selected in the present study to test this causal nexus. Findings of time and frequency dynamic analysis reveal that economic growth causes credit for the agriculture sector in the long run. However, the results show that the causality is running from manufacturing sectoral credit to growth, and credit for the manufacturing sector causes economic growth. Moreover, there is a positive correlation between economic growth and credit for the service sector. Remarkably, the findings stress that the direction of sectoral credit-growth causality nexus varies and depends on the type of sector. To the best of our knowledge, this is the first study that conducts this nexus, and results have important policy implications for policymakers and the Australian government.

Keywords: Sectoral Credit; Economic Growth; Wavelet; Australia.

\section{JEL Classification: G0; G2; O4}

\section{Introduction}

Although the connection between finance and growth is well-considered, both theoretical and empirical research provides an unclear understanding of the 
existence of this association, and the topic stays the subject of discussion. Theoretically, numerous scholars argued that finance leads growth (Schumpeter, 1911; Gurley \& Shaw, 1955) while some studies supported either the opposite view (Van Wijnbergen, 1983) or no linkage (Andersen \& Tarp, 2003). Empirically, in the related literature, the findings of numerous studies also established the obscurity in the interconnection between growth and finance (Uddin et al., 2013). Whereas there is extensive literature that has considerably studied the financegrowth nexus, numerous researches have also examined the credit-growth linkage (Ceccheti et al., 2011; Arcand et al., 2015) and bank credit supply- growth in particular (e.g., Kirikkaleli \& Athari, 2020). What about the link specifically between sectoral credit and growth?

The question of the dynamic nexus of sectoral credit-economic growth in Australia remains relevant for researchers. Historical antecedent points to the disruptive role of economic fluctuations on the credit market transmitting significant shocks to active sectors in the country (Kent \& D'Arcy, 2001). In this regard, some studies in the extant literature empirically isolate the impact of the credit shocks in examining its economy-wide effects. However, no attempt is yet made to study the disaggregated causal impact of such credit shocks on a sectoral basis for the Australian economy. This set the current study apart. The Australian economy has in recent time witnessed a decrease in its monthly year-on-year (YoY) domestic credit growth for most of the $1^{\text {st }}, 2^{\text {nd }}$, and $3^{\text {rd }}$ quarter of 2020 due to the disruptive impact of the recent global pandemic ${ }^{1}$. Credit growth in Australia reached an average of $9.1 \%$ between December 2002 and June 2020 recording a historical $59.1 \%$ as of May 2020 in relation to its lowest average of $0.2 \%$ in November $2009^{2}$. The recently released report by the World Development Indicators (WDI) shows that in 2019, domestic credit was $136 \%$, whereas it estimates Australian domestic credit to the private sector (\% of GDP) as $139 \%$ in 2018. For 2016, it was around $142 \%$ and about $128 \%$ in 2014 . The fluctuation in the domestic credit level can be linked to the health of the financial system in Australia affecting credit supply in the nation in general. From the foregoing between 2014 and 2016, domestic credit increases significantly before the downward spiral of 2018 and 2019. Thus, expectedly as the economy strengthens, credit demand will be stimulated--albeit unevenly across the economic sectors in the country.

The highlighted scenario above makes Australia of interest for researchers in studying the dynamic nexus of sectoral credit and economic growth. Particularly of interest are the agricultural, manufacturing, and service sector in the country. Data evidence shows that the Australian agricultural sector accounts for about $11 \%$ in export of goods and services in 2018-19 and 2.2\% value add to GDP with about

\footnotetext{
${ }^{1}$ https://tradingeconomics.com/australia/private-sector-credit

${ }^{2}$ https://www.ceicdata.com/en/indicator/australia/domestic-credit-growth
} 
Examining the Sectoral Credit-Growth Nexus in Australia: A Time and Frequency Dynamic Analysis

$20.6 \%$ contribution to employment ${ }^{3}$. The manufacturing sector is the country's $7^{\text {th }}$ largest sector in terms of employment and the $6^{\text {th }}$ output contributor to the country. This sector adds about $5.7 \%$ to Australian GDP annually ${ }^{4}$. Lastly, the Australian service sector significantly make-up about $70 \%$ of its GDP employing 4 of every 5 Australians, and contributes nearly $40 \%$ to the country's export earnings ${ }^{5}$. To our best knowledge, few empirical studies ${ }^{6}$ specifically, investigate the linkage between growth and sectoral credit causal in developing and developed markets. Hence, to fill the gap, this study aims to shed some light on the sectoral creditgrowth nexus and contribute to the existing empirical literature by focusing on the agriculture, manufacture, and service sectors in the case of Australia for the wide range period between 1994Q4 and 2018Q4. Also, despite investigating the timedimension causality between the variables in question, this study has a novelty to investigate the time and frequency dynamic causality between sectoral credit and economic growth. Besides, despite analyzing the time-dimensional causal relationships between the variables in question, this research has an innovation to explore the time and frequency causal linkage between growth and sectoral credit. This is the first paper to conduct this nexus, and the findings of this study are expected to open new discussions about the notion. This analysis provides some reliably impressive insights. Firstly, the sectoral credit- growth time and frequency dynamic analysis results show that economic growth causes credit for the agriculture sector in the long run. Second, among the sectors, the causality is running only from manufacturing sectoral credit to growth, and credit for the manufacturing sector causes economic growth. Third, there is a feedback causality between credit for the service sector and economic growth.

The remaining part of this research proceeds thus. Section 2 portrays a summary of existing literature from an empirical and theoretical perspective. Section 3 discusses empirical methodology followed. Section 4 illustrates the findings and discussions. The study concludes in Section 5.

\footnotetext{
${ }^{3}$ https://www.agriculture.gov.au/abares/publications/insights/snapshot-of-australianagriculture-2020

${ }^{4}$ https://cdn.aigroup.com.au/Economic_Indicators/Economic_Outlook/Australian_Manufact uring_in_2019.pdf

${ }^{5}$ https://www.dfat.gov.au/trade/services-and-digital-trade/Pages/the-importance-ofservices-trade-toaustralia\#: : text=The $\% 20$ services $\% 20$ sector $\% 20$ makes $\% 20$ up,out $\% 20$ of $\% 20$ every $\% 20$ five $\% 20$ Australians.\&text $=$ In $\% 202019 \% 2 \mathrm{C} \% 20$ services $\% 20$ made $\% 20 u p \% 2021.6 \% 25 \% 20$ of $\% 20$ Australia's\%20total\%20xports.

6 For example, the study of Rajan and Zingales (1998) established that financial development has a positive effect on economic growth and on manufacturing sectors that use more foreign financing to expand significantly quickly in economies with more mature financial markets.
} 
Seyed Alireza Athari, Dervis Kirikkaleli, Isah Wada, Tomiwa Sunday Adebayo

\section{Literature Review}

The theoretical relationship between domestic credit and real economic growth has been espoused considerably over the past decades. Schumpeter (1911), through his seminal work on economic growth and development, documented firsthand the role of private credit by the financial institution in stimulating aggregate output growth. Thus, there is little debate about the role of credit in general in facilitating economic growth. The leading contribution of McKinnon (1973) and Shaw (1973) gives added impetus to the role of credit via the activities of financial institutions in promoting economic growth. Whereas the positive role of credit in the credit-economic growth nexus is well documented, in extant studies, the adverse impact is also recorded. Prominent researchers have highlighted various positive channels through which credit supply in the economy support aggregate output growth-such as via credit allocation role, portfolio diversification, liquidity stimulation, risk reduction, and financial intermediary productivity boost (Gurley \& Shaw, 1955; Rajan \& Zingales, 1998; Rousseau \& Wachtel, 2000).

Conversely, other categories of authors argued that financial credit allocation impact output growth negatively (Van Wijnbergen, 1983). To support this opinion, proponents stressed the limited role of financial credit allocation in the credit-economic growth nexus (Andersen \& Tarp, 2003). Authors have also shed light on the causality of domestic credit and economic growth nexus (see Partick, 1966; Gurley \& Shaw, 1967; Odhiambo, 2008). This channel of causality is documented as the 'supply leading' and 'demand following' hypothetical responses (Partick, 1966). Thus, when output growth is the resultant effect of credit expansion, the supply leading hypothesis takes hold (see, Mckinnon, 1973; Shaw, $1973 \mathrm{Kondoz}$ et al. 2020). Alternatively, when output growth causes more credit injection in the economy, the demand following hypothesis results (see Gurley \& Shaw, 1967; Kondoz et al., 2020). Invariably, a bi-directional nexus gives the feedback hypothesis (Kondoz et al., 2020).

In related studies, the nexus of sectoral credit and economic growth have established substantial devotion with the earlier scholars (Schumpeter, 1911; Patrick, 1966) theorizing divergent opinion on the role of financial sector credit in economic growth. The pioneering research of Schumpeter (1911) showed that the sectoral reallocation of credit to a more productive sector helps to spur more rapid economic growth. The study by Rajan \& Zingales (1998) empirically revealed that financial credit to the industrial sector accelerates economic growth. However, Rajan \& Zingales (1998) maintained that the correlation in credit-economic growth nexus does not imply causality. The contribution of Christopoulos and Tsionas (2004) examining a list of 10 emerging countries equally found uni-directional causality in their finance-growth study justifying the credit supply-leading hypothesis. While Odhiambo (2008) empirically observed a one-way causality from growth to financial development not the reverse for Kenya. In a panel study by Acaravaci et al. (2009) for a total of 24 nations in sub-Saharan Africa, evidence 
Examining the Sectoral Credit-Growth Nexus in Australia: A Time and Frequency Dynamic Analysis

existed simultaneously of both demand- and supply-following responses within the data.

In the extent studies, a plethora of related academic literature has espoused the significance of financial sector development in explaining the dynamic nexus of credit and economic growth (Kirikkalelia \& Athari, 2020). Studies have shown that the contraction of credit supply negatively impacts real output for the OECD region. Authors have also empirically reported that the development of financial sector credit help to boost growth for India and European nations (Mishra et al., 2009). Empirical studies have also suggested that there exists a threshold beyond which financial credit adversely affects economic growth such as between 90 and 100 percent of GDP, respectively (Arcand et al., 2015). In terms of sectoral credit allocation, mixed evidence is documented in the extant literature on the dynamic impact of credit allocation on output growth and development. Using panel data with fixed effect regression, Hartarska et al. (2015) reported a significant positive relationship between agricultural sector lending and agricultural sector GDP for rural areas in the US. Seven \& Tumen (2020) also empirically found that agricultural sector credit and agricultural output moves in a positive direction in a cross-country study for Turkey. Their evidence showed that by doubling agricultural sector credit, agricultural output increases about 4 - 5\%. Rehman et al. (2017) evidenced a significant association between agricultural credit and agricultural GDP for Pakistan. For overall economic growth impact, Humphries \& Knowles (2010) using an augmented Solow-Swan economic growth model gave robust findings supporting the impact of agricultural sector productivity on economic growth. The contribution of the manufacturing sector to economic growth is well mentioned in the empirical studies. Research evidence shows that manufacturing is a significant cornerstone for economic output expansion in the US providing manufactured goods to other sectors.

The merit of credit allocation to the manufacturing sector towards economic growth is well mentioned in the empirical studies (Tunali \& Boru 2019). Evidence shows that manufacturing is a significant cornerstone of economic output expansion in the US (US Department of Commerce, 2004). According to Tunali \& Boru (2019), manufacturing sector credit enhances economic growth through backward and forward integration, technical knowledge spillover, and on-job skill development. Nevertheless, Tunali \& Boru (2019) empirically found no causality between the manufacturing sector, service sector, and economic growth in Turkey. The study of Szirmai \& Verspagen (2015) elaborate on the diminishing role of the manufacturing sector regarding real growth. The evidence regards manufacturing as a more strenuous route for economic growth beginning from the 1990s. Nevertheless, the historical role of the manufacturing sector as an engine of economic growth and development remains very relevant. Studies generally agree that adequate credit or capital allocation to the manufacturing sub-sector is a veritable catalyst for economic output expansion. Utilizing a stochastic inputoutput frontier model of Australia industrial level data, Mahadevan (2010) opined that until the 1970s manufacturing input growth caused more output contribution to 
GDP. Nowadays, evidence shows that the productivity of the total factor has been the leading contributor to growth in the country-motivated by the rapid credit expansion for research and development (R\&D) (Mahadevan, 2010).

Remarkably, the finding of Kim (2019) in a cross-industrial study for the impact of R\&D investment on growth for 14 countries generally supports the empirical finding of Mahadevan (2010). The evidence using an index constructed by Herfindahl-Hirschman found a U-shaped inverted nexus between R\&D investment concentration and economic growth. The study also that finds R\&D investment concentration is beneficial in the short-run across the sector but detrimental for growth over the long-run. Nonetheless, Kim (2019) founds that R\&D investment for the high-technological manufacturing sector reduces the adverse impact of such concentration on economic growth for the countries examined. Conversely, the study reported the direct opposite for the service sector stressing the importance of strategic choice for sectoral investment and economic diversification. Moreover, Sim (2005) employed the two-sector-two-factor endowment endogenous model to examine the merit of sectoral investment diversification. The study found that by liberalizing the service sector and with adequate credit injection, the economic equilibrium is altered towards a more highly specialized modern sector. Also, Bisrat (2019) while examining the dynamic service sector-labor productivity convergence for 160 countries regarded the service as a significant lead sector for labor productivity catch-up ahead of the manufacturing sector. Finally, Liang \& Long (2016) studied the role of government intervention via taxes and lump-sum credit transfer given sectoral productivity and structural transformational growth. The study showed that during a steady-state equilibrium, with productivity growth in economic sectors, government intervention through tax reduction causes the share of agricultural employment in GDP to reduce whilst encouraging growth in the service sector contribution to national output.

In the literature examined, the nexus between sectoral credit and economic growth vague with mixed findings. Many researchers empirically document evidence that justifies the imperative of financial credit for economic growth and development. Although, few studies exist in the extant literature with finding contrary to the aforementioned direct positive augmenting role of credit as an impetus of economic growth. Nonetheless, there is a rarity of studies examining the sectoral impact or effect of credit contribution to overall economic growth. Even more so, the choice of 3 leading economic sectors; namely, agriculture, manufacturing, and service as well as the adopted novel methodological approach gives significant currency to this study. Although, studies abound that have generally considered an array of both developed and developing countries in their empirical research. We observed that very few have more robustly explored the sectoral impact of financial credit for growth in Australia for the selected agriculture, manufacturing, and service industry in broad terms. These are more open to a significant gap in the literature. Thus, the current study adequately 
Examining the Sectoral Credit-Growth Nexus in Australia: A Time and Frequency Dynamic Analysis

undertakes to fill the identified research gap for the case of Australia adopting the novel wavelet coherence test technique for the period between 1994Q4 to 2018Q4.

\section{Empirical Methodology}

\subsection{Description of Data}

The study aims to examine the nexus between sectoral credit and economic growth in Australia utilizing quarterly data between 1994 and 2018Q (96 observations). Due to data unavailability and to solve the limited sample size issue, we utilize a quadratic match-sum method in converting yearly data to quarterly data. This transformation method has been used by previous studies (e.g., Kirikkaleli \& Athari, 2020), and it is effective to diminish point-to-point adjustments and changing seasonal disparities via the transformation of low to high-frequency data. Furthermore, the dataset is converted into its natural logarithm. This was implemented to ensure conformity to normality. In this paper, the dependent variable is economic growth which is calculated as GDP per capital US\$2010. In addition, the independent variable is sectoral credit, which is divided into three distinct parts namely; credits for manufacturing sector, credits for agriculture sector and credits for service sector. This study collected the agriculture, manufacturing, and service sectoral credits from Reserve Bank of Australia $^{7}$. Table 1 shows a brief description of the dataset used in this study. The findings show that all variables are normally distributed as revealed by the skewness. Furthermore, the kurtosis revealed that only economic growth and credits for agriculture conform to normality while credits for manufacturing sector and credits for service sector does not conform to normality.

The Jarque-Bera probability reveals that credits for agriculture sector and credits for manufacturing sector are normally distributed whereas credits for service sector and economic growth are not normally distributed.

Table 1. Data and Descriptive Statistics (1994Q1-2019Q1)

\begin{tabular}{lcccc} 
Variable & $\begin{array}{c}\text { Credits for } \\
\text { Agriculture Sector }\end{array}$ & $\begin{array}{c}\text { Credits for } \\
\text { Manufacturing } \\
\text { Sector }\end{array}$ & $\begin{array}{c}\text { Credits for } \\
\text { Service } \\
\text { Sector }\end{array}$ & $\begin{array}{c}\text { Economic } \\
\text { Growth }\end{array}$ \\
\hline Code & Agriculture & Manufacturing & Service & Growth \\
\hline Mean & 1.788179 & 1.242869 & 1.723678 & 3.239366 \\
Median & 1.298767 & 1.248743 & 1.757397 & 2.993171 \\
Maximum & 10.30301 & 11.38788 & 13.08851 & 5.646777 \\
Minimum & -4.459475 & -12.36241 & -8.962349 & 1.123658 \\
Std. Dev. & 2.909468 & 4.120122 & 3.477822 & 1.091864 \\
Skewness & 0.384809 & -0.154423 & -0.038856 & 0.376460 \\
Kurtosis & 2.984002 & 3.555923 & 4.785932 & 2.207512 \\
Jarque-Bera & 2.493722 & 1.702001 & 13.44812 & 5.028644 \\
Probability & 0.287406 & 0.426988 & 0.001202 & 0.080918 \\
\hline
\end{tabular}

${ }^{7}$ www.rba.gov.au 
Seyed Alireza Athari, Dervis Kirikkaleli, Isah Wada, Tomiwa Sunday Adebayo

In addition, Figure 1 illustrates the trends in economic growth and sectoral credit between 1994Q1 and 2018Q4.

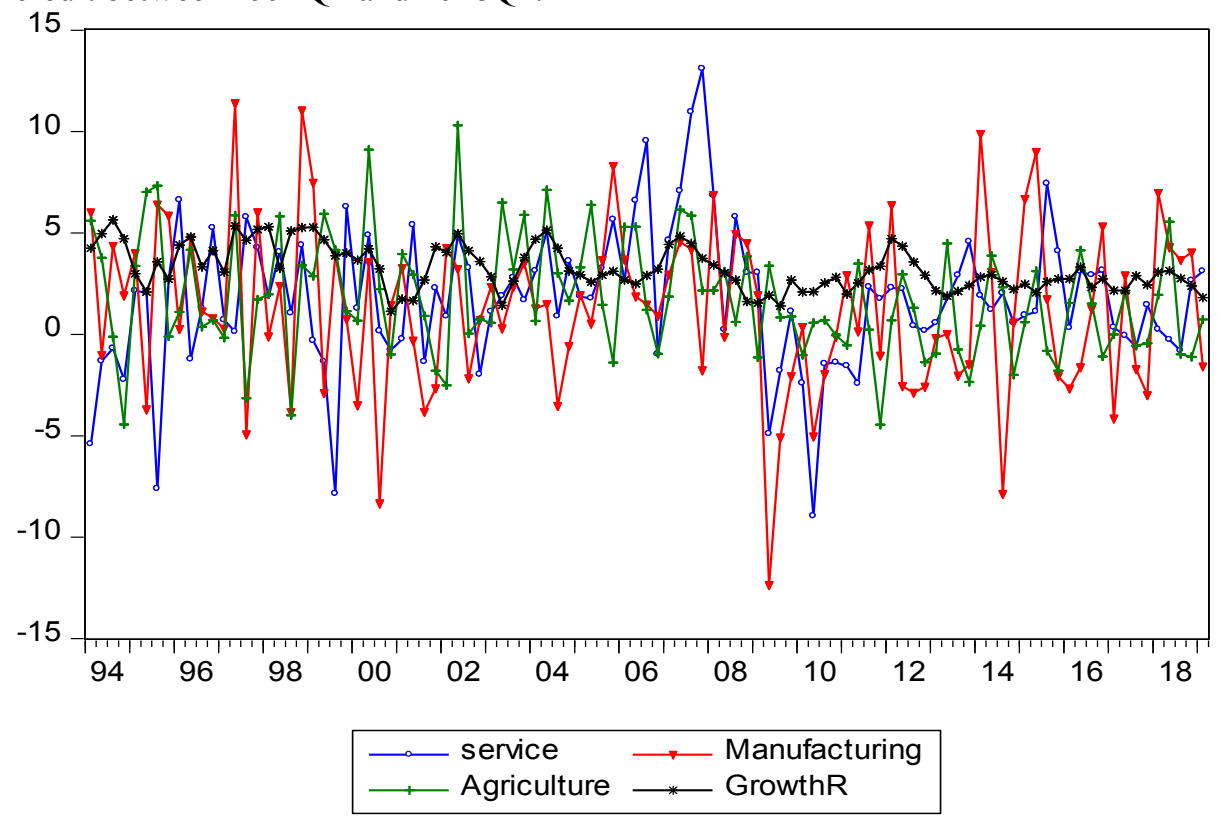

Figure 1. Trends in sectoral credit and economic growth

\subsection{Econometrics Methodology}

Although there are several traditional unit root tests including Phillips and Perron (PP), Dickey-Fuller (DF), and including Augmented Dickey-Fuller (ADF), we used the Zivot-Andrew unit root test initiated by Zivot \& Andrews (2002) to capture stationarity features and structural break in series. This is because if there is a break in the series, the traditional unit root tests will yield misleading outcomes. The Zivot-Andrew unit root test not only tests the unit root characteristics of each variable but consider single break. The Zivot \& Andrew (2002) Equation is depicted as follows:

Model 1: $\Delta x_{t}=\varphi+\varphi x_{t-1}+\pi t+\delta D U_{t}+\sum_{j=1}^{k} d_{j} \Delta x_{t-j}+\mu_{t}$

Model 2: $\Delta x_{t}=\varphi+\varphi x_{t-1}+\pi t+\gamma D T_{t}+\sum_{j=1}^{k} d_{j} \Delta x_{t-j}+\mu_{t}$

Model 3: $\Delta x_{t}=\beta+\beta x_{t-1}+\beta t+\theta D U_{t}+\theta D T_{t}+\sum_{j=1}^{k} d_{j} \Delta x_{t-j}+\mu_{t}$

Where $D U_{t}$ is an indicator dummy variable for mean shift occurring at each possible break-date (TB) while $D T_{t}$ is the respective trend shift variable. Formally, 
Examining the Sectoral Credit-Growth Nexus in Australia: A Time and Frequency Dynamic Analysis

$$
D U_{t}=\left\{\begin{array}{l}
1 \ldots \text { if } t>T B \\
0 \ldots . \text { if } t<T B
\end{array} \text { and } D T_{t}=\left\{\begin{array}{l}
t-T B \ldots \text { if } t>T B \\
0 \ldots . \quad \text { if } t<T B
\end{array}\right.\right.
$$

There are three options when implementing the Zivot-Andrews unit-root test, comprising at the intercept, trend, and both intercept and trend. Model 1 (Eq. 1) depicts Zivot-Andrews at the intercept, Model 2 (Eq. 2) depicts Zivot-Andrews at Trend, and Model 3 (Eq. 3) depicts Zivot-Andrews at both intercept and Trend which is chosen in our analysis. In the three models (Models 1 to 3), the null hypothesis is $\mathrm{H}_{0}=0$, which demonstrates that the series $\mathrm{x}_{\mathrm{t}}$ encompasses a unit-root with a drift that disregards any structural break, whereas the alternative hypothesis $\mathrm{Ha}<0$ illustrates that the series is a trend-stationary process with single break showing at an unidentified point in time. Furthermore, this study utilized the timefrequency dependence to investigate the causal impact of credits for the agriculture sector, credits for the manufacturing sector, and credits for the service sector on Australia's economic growth. The current paper utilized Zivot \& Andrews unit root test to explore the integration order of the series in the presence of structural break. Therefore, we analyze the time and frequency interconnection between economic growth and sectoral credit by utilizing the wavelet coherence technique. The innovation of this technique is that it merges time-domain and frequency-domain causalities. Thus, this current paper enables us to catch the causality and correlation between sectoral credit and economic growth in the short-run, mediumrun, and long-run respectively. As stated by Kondoz et al. (2019) and Kirikkaleli \& Athari (2020), a multiscale decomposition technique offers a natural intuition for frequency-dependent features to disclose the linkage between economic growth and sectoral credit. The novelty of wavelet methods can be observed where the decomposition of one-dimensional time-series into the bi-dimensional timefrequency range is allowed. This enables us to catch the causal impact of sectoral credit on growth in the short, medium, and long-run. Goupillaud et al. (1984) initiated this method. The current paper uses the $\varpi$ wavelet technique, which is an element of the Morlet family wavelet. Equation 5 illustrates the Morlet wavelet family as follows;

$$
\varpi(t)=\pi^{-\frac{1}{4}} e^{-i \varpi t} e^{-\frac{1}{2} t^{2}}
$$

The $w$ shows the frequency used premised on the constrained time series; i demonstrates $\mathrm{p}(t), n=0,1,2,3 \ldots \mathrm{N}-1$; and $\sqrt{-1}$. Also, there is a time conversion to the time-frequency domain that associates with the wavelet. $\varpi$ is transformed; thus, it is changed into $\varpi_{k, f}$, as revealed in Equation 6.

$$
\varpi_{k, f}(t)=\frac{1}{\sqrt{h}} \varpi\left(\frac{t-k}{f}\right), k, f \in \mathbb{R}, f \neq 0
$$


Seyed Alireza Athari, Dervis Kirikkaleli, Isah Wada, Tomiwa Sunday Adebayo

The time-series $p(t)$ is integrated. Thus Equation 7 shows the continuous wavelet function.

$$
\varpi_{p}(k, f)=\int_{-\infty}^{\infty} p(t) \frac{1}{\sqrt{f}} \varpi\left(\overline{\frac{t-k}{f}}\right) d t,
$$

The coefficient $(\psi)$ is merged into the Equation, and Equations 8 and 9 are restored.

$$
p(t)=\frac{1}{C_{\varpi}} \int_{0}^{\infty}\left[\int_{-\infty}^{\infty}\left|\mathfrak{w}_{p}(a, b)\right|^{2} d a\right] \frac{d b}{b^{2}}
$$

The volatility in of credits for agriculture sector, credits for service sector, economic growth, and credits for manufacturing sector is captured by the wavelet power spectrum (WPS) which is depicted in Equation 9 as follows;

$$
W P S_{p}(k, f)\left|W_{p}(k, f)\right|^{2}
$$

The series in Equations 10 and 11 are converted by the Cross-Wavelet Transformation (CWT) as follows;

$$
W_{p q}(k, f)=W_{p}(k, f) \overline{W_{q}(k, f)}
$$

Where the two time series are depicted by $W_{p}(k, f)$ and $W_{q}\left(k_{2} f\right)$ and squared wavelet coherence is illustrated in Equation 10 as follows:

$$
R^{2}(k, f)=\frac{\left|S\left(f^{-1} W_{p q}(k, f)\right)\right|^{2}}{S\left(f^{-1}\left|W_{p}(k, f)\right|^{2}\right) S\left(f^{-1}\left|W_{q}(k, f)\right|^{2}\right)}
$$

If the $R^{2}(k, f)$ approaches 1 , it portrays correlation and causal linkage between the two series at a precise level, bounded by a black line. In addition, if $R^{2}(k, f)$ approaches 0 , it portrays no evidence of causal and correlation between the two series. Nonetheless, $R^{2}(k, f)$ cannot offer any comprehensive facts on the sign of correlation. Thus, Torrence \& Compo (1998) proposed a process for capturing discrepancies in wavelet coherence (WTC) by utilizing deferral signs in the wavering of two-time series. Equation 12 thereby elucidates the WTC as follows;

$$
\phi_{p q}(k, f)=\tan ^{-1}\left(\frac{L\left\{S\left(f^{-1} W_{p j}(k, f)\right)\right\}}{o\left\{S\left(f^{-1} W_{p j}(k, f)\right)\right\}}\right)
$$


Examining the Sectoral Credit-Growth Nexus in Australia: A Time and Frequency Dynamic Analysis

An imaginary operator and a real part operator are illustrated by $L$ and $O$ separately.

\section{3 Empirical Results}

As an initial test, we capture the order of integration and a single break in series by utilizing Zivot \& Andrew's (2002) unit root test before investigating the time-frequency dependency between economic growth and sectoral credit in Australia. Compared to the traditional unit root tests, the Zivot-Andrews unit root test considers one-break in the series. Table 2 depicts the outcome of the ZivotAndrews unit root test at constant $(\mathrm{C})$ and constant and trend $(\mathrm{C} \& \mathrm{~T})$. The findings reveal that at level i.e. $\mathrm{I}(0)$, all the variables at stationary at $\mathrm{C}$ and $\mathrm{C}$ and $\mathrm{T}$ with the exemption of economic growth. However, after taking the first difference, i.e. I(1), all the are stationary at $\mathrm{C}$ and $\mathrm{C}$ and $\mathrm{T}$ respectively.

Table 2: Zivot-Andrews Unit Root Test

\begin{tabular}{ccccc}
\hline \multicolumn{5}{c}{ Series in Levels } \\
\hline \multirow{3}{*}{$\mathrm{C}$} & Agriculture & Manufacturing & Service & Growth \\
\cline { 2 - 5 } & $-5.311^{* * *}$ & $-10.476^{* * *}$ & $-4.677^{*}$ & -4.167 \\
& $(2009 \mathrm{Q} 1)^{* * *}$ & $(2009 \mathrm{Q} 2)^{* * *}$ & $(2009 \mathrm{Q} 2)^{* *}$ & $(2000 \mathrm{Q} 3)^{* *}$ \\
$\mathrm{H} \& \mathrm{~T}$ & $-5.195^{* *}$ & $-10.861^{* *}$ & -4.568 & -4.339 \\
& $(2009 \mathrm{Q} 1)^{* * *}$ & $(2009 \mathrm{Q} 2)^{* * *}$ & $(2009 \mathrm{Q})^{* * *}$ & $(1992 \mathrm{Q} 2)$ \\
\cline { 2 - 5 } $\mathrm{C}$ & \multicolumn{4}{c}{ Series in First Differences } \\
\cline { 2 - 5 } $\mathrm{C}$ & $-7.434^{* * *}$ & $-8.181^{* * *}$ & $-10.448^{* * *}$ & $-9.498^{* * *}$ \\
& $(2004 \mathrm{Q} 3)^{*}$ & $(2010 \mathrm{Q} 3)$ & $(2008 \mathrm{Q} 1)$ & $(1999 \mathrm{Q} 1)^{* * *}$ \\
$\mathrm{C} \& \mathrm{~T}$ & $-7.457^{* * *}$ & $-8.150^{* * *}$ & $-10.485^{* * *}$ & $-9.589^{* * *}$ \\
& $(2002 \mathrm{Q} 2)^{* * *}$ & $(2000 \mathrm{Q} 4)^{* *}$ & $(2009 \mathrm{Q} 2)^{* * *}$ & $(2001 \mathrm{Q})^{* * *}$ \\
\hline
\end{tabular}

Note: $C$ and $C \& T$ denote constant and constant and trend correspondingly. The significance level of $0.01,0.05$ and 0.10 is denoted $* * *, * *$ and $*$, respectively. The numbers in parenthesis () represent breakpoint.

The study utilized the continuous wavelet transformation to capture the volatility of credits for the sectors including agriculture, service, manufacturing, and economic growth in Australia's between 1994Q1 and 2018Q4. Figures 2, 3, 4, and 5 depict the WPS of credits for the agriculture sector, credits for the service sector, credits for the manufacturing sector, and economic growth, respectively. We utilized the "bivariate" package in R statistical software to obtain information for time-series variables. Based on the dataset covering the timeframe between 1994Q1 and 2018Q4, the study chooses 32 periods. In Figure 2-5, the cone of influence (COI) is depicted by the white cone-shaped line, which denotes an area where wavelet power is affected while the thick black contour denotes a significant level of 5\% calculated by Monte Carlo simulations. Figure 2 shows the WPS of credits for the agriculture sector in Australia and findings reveal vulnerability at high frequency from 1995-1996, 1999-2002, 2005, and 2011-2013. Figure 3 
Seyed Alireza Athari, Dervis Kirikkaleli, Isah Wada, Tomiwa Sunday Adebayo

reveals the WPS of credits for the manufacturing sector in Australia and findings reveal volatility at high and medium frequencies from 1999-1998, 2009-2013, and 2013-2015. Figure 4 illustrates the WPS of credits for the service sector in Australia between 1994Q1 and 2018Q4. At different frequencies, there is evidence of vulnerability from 1994-1995 and 2003-2013. Figure 5 depicts the WPS of economic growth between 1994Q1 and 2018Q4. The outcome reveals evidence of vulnerability at high and medium frequencies from 1996-1999 and 2004-2004.

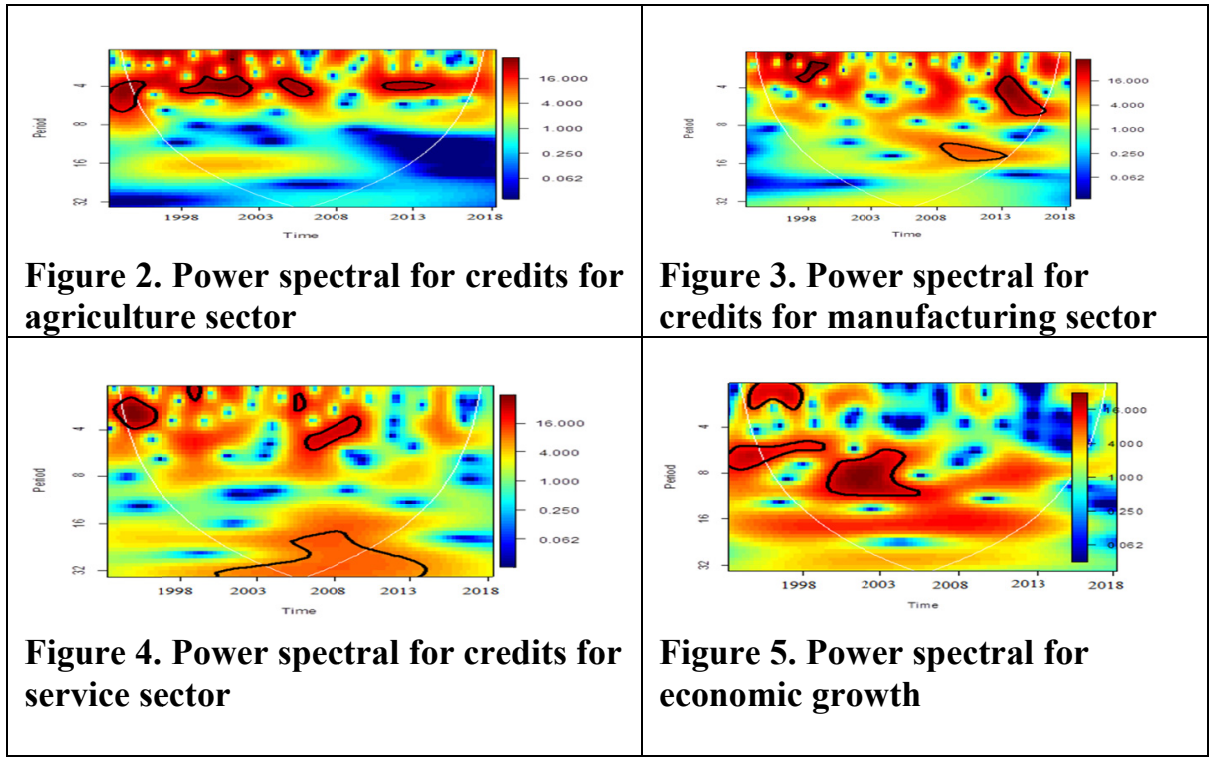

After the vulnerability in the series was established, we utilized the wavelet coherence (WTC) to catch the time-frequency dependence of (a) credit for the agriculture sector and economic growth; (b) credit for the manufacturing sector and economic growth; and (c) credit for the service sector and economic growth. Figures, 6-8, depicts the cone of influence when interpretation is made. The color scale at the right side in Figures 6-8, illustrates the strength of correlation/ causality between series. The rightward and leftwards arrows illustrate phase (positive correlation) and anti-phase (negative correlation) between the two-time series. Furthermore, the rightward-up (leftward-down) illustrates that the first series lead the second series while the leftward-up (rightward-down) demonstrates that the second series lead the first series. Besides, in Figures 6-8, the warmer color (red) illustrates evidence of correlation whereas the cold color (blue) illustrates no correlation between the two-time series. Figure 6 shows the WTC between economic growth and credit for the agriculture sector in Australia between 1994Q1 and 2018Q4. At scale, 16-32 in the long-term, the majority of the arrows are rightward which depicts in-phase linkage between credit for the agriculture sector 
Examining the Sectoral Credit-Growth Nexus in Australia: A Time and Frequency Dynamic Analysis

and economic growth. Furthermore, the rightward-up arrows reveal that economic growth causes credit for the agriculture sector in the long-run. This shows that economic growth can predict significant variation in credit for the agriculture sector. Results are consistent with the prediction of the studies by Gurley and Shaw (1967) and Kondoz et al. (2020), and underline that the demand following hypothesis holds for the agriculture sector.

Figure 7 shows the WTC between credit for the manufacturing sector and economic growth in Australia between 1994Q1 and 2018Q4. At scale, 16-13 in the long-run, majority of the arrows are rightward and down which demonstrates evidence of positive interconnection between credit for the manufacturing sector and economic growth in Australia between 2000 and 2009. This implies that an increase in credit for the manufacturing sector is accompanied by economic growth and vice-versa in Australia. Additionally, the rightward-down arrows suggest a one-way causality running from credit for the manufacturing sector to economic growth. This shows that credit for the manufacturing sector can predict economic growth in Australia. Thus, findings stress that the supply leading hypothesis is verified for the Australian manufacturing sector, which implies that output growth is the resultant effect of credit expansion (see, Mckinnon, 1973; Shaw, 1973). Figure 8 illustrates the WTC between credit for the service sector and economic growth in Australia between 1994Q1 and 2018Q4. At different frequencies, the arrows pointing rightward down and up imply the interconnection between credit for the service sector and economic growth. This shows that the increase in credit for the service sector is accompanied by an increase in economic growth. Also, there is evidence of causality running from economic growth to credit for the service sector. Results support the feedback hypothesis and show that there is a bidirectional nexus between credit for the Australian service sector and economic growth (Kondoz et al., 2020). Remarkably, the findings stress that the direction of sectoral credit-growth causality nexus varies and depends on type of sector.

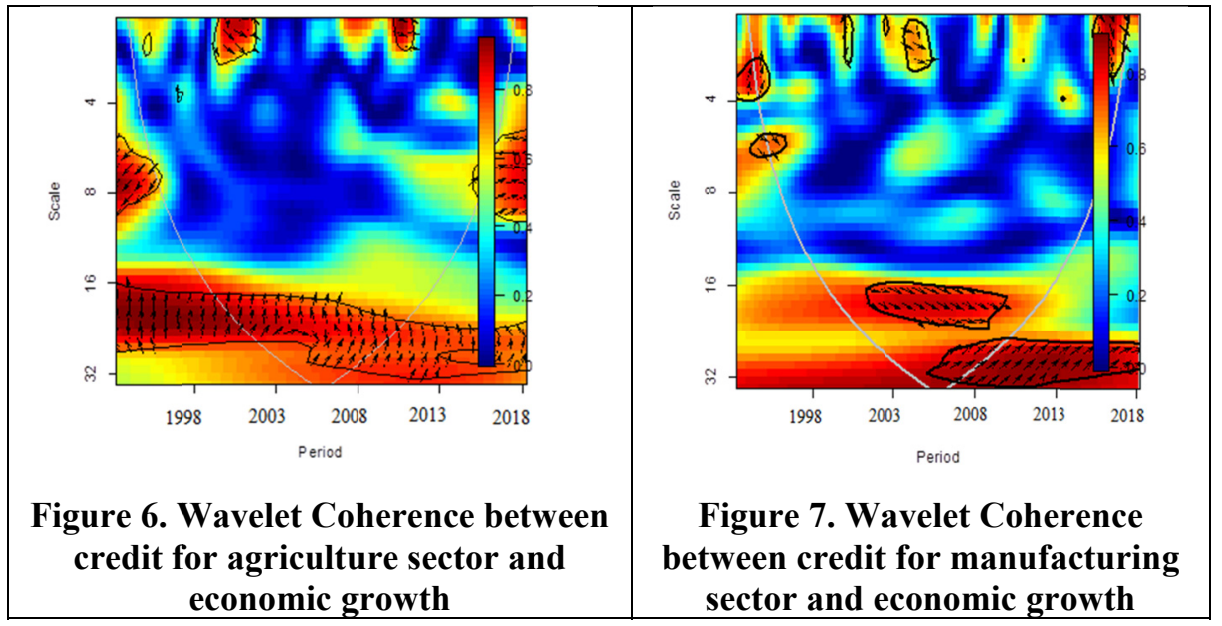


Seyed Alireza Athari, Dervis Kirikkaleli, Isah Wada, Tomiwa Sunday Adebayo

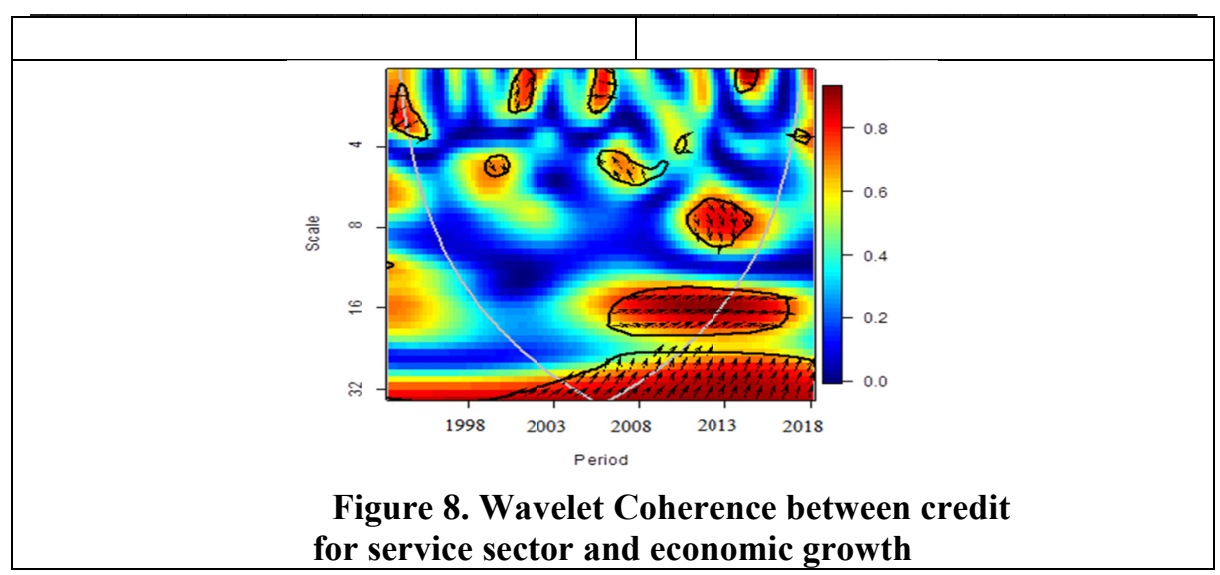

\section{Conclusions}

Although several studies have investigated the credit-growth nexus, few studies have empirically investigated the link between sectoral credit and economic growth. To the best of knowledge, this is the first study to conduct the sectoral credit and growth causal nexus by focusing on the agriculture, manufacture, and service sectors of Australia using a wavelet coherence test between 1994Q4 and 2018Q4. Results of the wavelet coherence test reveal that economic growth causes credit for the agriculture sector in the long run whereas the causality is running from manufacturing sectoral credit to growth. Moreover, there is a positive association between credit for the service sector and economic growth. The findings stress that the direction of sectoral credit-growth causality nexus varies and depends on the type of sector. The policy implications of the study are significant in many respects. Firstly, the empirical long-run causality of economic growth and agricultural sector credit implies that economic growth, in general, precedes agricultural sector growth and development. This confirms that the Australian economy is far less dependent on the agriculture sector for its economic growth. Thus, credit expansion policy to the agriculture sector must be implemented with caution to avoid crowding out the other significant economic sectors in the country. Moreover, the result refutes the notion of a resource-based status for the Australian economy. Secondly, the empirical evidence of unidirectional causality from manufacturing sector credit to economic growth explains the reliance of the Australian economy on the modern manufacturing industrialization process in promoting economic growth. The policy implication of this finding suggests that the Australian government's economic policy to reduce credit expansion to the manufacturing sector might result in diminishing output, hence deteriorating impact on economic growth. The empirical finding in respect of the service sector suggests a bi-directional causality nexus between the service sector and economic growth in Australia, and the credit expansion of the service sector leads to enhance economic growth and vice-versa. 
Examining the Sectoral Credit-Growth Nexus in Australia: A Time and Frequency Dynamic Analysis

In summing up, the Australian government should prioritize credit expansion to its manufacturing sector while not neglecting the duo of the agriculture and service sector in the country to achieve a more balanced economic output expansion. Thus, whereas the supply leading hypothesis is verified for the Australian manufacturing sector, the demand following hypothesis holds for the agriculture sector, respectively. Besides, the feedback hypothesis service sector is valid for the Australian service sector. For further studies, it would be valuable to take the credits for both sectors and sub-sectors into their account to provide a comprehensive picture.

\section{REFERENCES}

[1] Andersen, T. B. and Tarp, F. (2003), Financial Liberalization, Financial Development and Economic Growth in LDCs. Journal of International Development: The Journal of the Development Studies Association, 15, 189-2091;

[2] Bisrat, K. (2019), The Rise of Services and Convergence in Labor Productivity among Countries. Applied Economics Letters, 26 (21), 1749-1755;

[3] Christopoulos, D. K., Tsionas, E. G. (2004), Financial Development and Economic Growth: Evidence from Panel Unit Root and Co-Integration Tests. Journal of Development Economics, 73, 55-74;

[4] Gurley, J. G., Shaw, E. S. (1955), Financial Aspects of Economic Development. The American Economic Review, 45, 515-538;

[5] Hartarska, V., D. Nadolnyak., Shen. X. (2015), Agricultural Credit and Economic Growth in Rural Areas. Agricultural Finance Review, 3, 302 - 312;

[6] Humphries, H., Knowles, S. (1998), Does Agriculture Contribute to Economic Growth? Some Empirical Evidence. Applied Economics, 6, 775-781; [7] Liang, J., Long, S. (2017), Government Intervention, Sectoral Productivity Growth and Structural Transformation. Applied Economics Letters, 24(16), 1181-1188;

[8] Kim, M. (2020), Cross-industry Distribution of R\&D Investments and Economic Growth. Applied Economics Letters, 8, 679-684;

[9] Kirikkaleli, D., Athari, S. A. (2020), Time-frequency Co-movements between Bank Credit Supply and Economic Growth in an Emerging Market: Does the Bank Ownership Structure Matter. The North American Journal of Economics and Finance, 101239;

[10] Kondoz, M., Kirikkaleli, D., Athari, S. A. (2020), Time-Frequency Dependencies of Financial and Economic Risks in South American Countries. The Quarterly Review of Economics and Finance;

[11] Mahadevan, R. (2002), Productivity Growth in Australian Manufacturing Sector: Some New Evidence. Applied Economics Letters, 9. 1017-23; [12] McKinnon, P. (1973), Money and Capital In Economic Development. Washington DC: Brookings Institution;

[13] Odhiambo, N. M. (2008), Financial Development in Kenya: A Dynamic

Test of the Finance-led Growth Hypothesis. Economic Issues, 2, 21-36; 
Seyed Alireza Athari, Dervis Kirikkaleli, Isah Wada, Tomiwa Sunday Adebayo

[14] Patrick, H. T. (1966), Financial Development and Economic Growth in Underdeveloped Countries. Economic development and Cultural change, 14, 174189 ;

[15] Rajan, R. G., Zingales, L. (1998), Financial Dependence and Growth. American Economic Review, 88, 559-586;

[16] Rehman, A., Chandio, A. A., Hussain, I., Jingdong, L. (2017), Is Credit the Devil in the Agriculture? The Role of Credit in Pakistan's Agricultural Sector. The Journal of Finance and Data Science, 3(1-4), 38-44;

[17] Szirmai, A., Verspagen, B. (2015), Manufacturing and Economic Growth in Developing Countries. Structural Change and Economic Dynamics, 46-59;

[18] Schumpeter, J. A. (1911), The Theory of Economic Development: An

Inquiry into Profits, Capital, Credit, Interest, and The Business Cycle. pp. 1934.

Cambridge: Harvard University Press., translated by Opie, R;

[19] Shaw, E. S. (1973), Financial Deepening in Economic Development. New

York: Oxford University Press;

[20] Sim, N. C. (2005), Service Liberalization, Endogenous Industrial

Composition and Modernization. Applied Economics Letters, 3, 161-163;

[21] Torrence, C., Compo, G. P. (1998), A Practical Guide to Wavelet Analysis. Bulletin of the American Meteorological society, 1, 61-78;

[22] Tunali C. B., Boru,F. (2019), The Causality Effects of Manufacturing

Sector on Some Macroeconomic Variables in Turkey. Procedia Computer

Science, 1109-1113;

[23] Uddin, G. S., Sjö, B., Shahbaz, M. (2013), The Causal Nexus between

Financial Development and Economic Growth in Kenya. Economic

Modelling, 35, 701-707;

[24] Van Wijnbergen, S. (1983); Credit Policy, Inflation and Growth in a

Financially Repressed Economy. Journal of Development Economics, 13, 45-65;

[25] Zivot, E., Andrews, D. W. K. (2002), Further Evidence on the Great Crash, the Oil-price Shock, and the Unit-root Hypothesis. Journal of business \&

economic statistics, $1,25$. 